\title{
Unpacking smart education's soft smartness variables: Leadership and human resources capacities as key participatory actors
}

\author{
Jonela Carmada Marisa Wilson ${ }^{1}\left[\right.$ (1) Patrick Kandege ${ }^{2}$ (1). \\ Akadje Jean Roland Edjoukou ${ }^{3} \cdot$ Mussie Tesfay Teklu ${ }^{1}$
}

Received: 18 February 2021 / Accepted: 20 May 2021 / Published online: 18 June 2021

(c) The Author(s), under exclusive licence to Springer Science+Business Media, LLC, part of Springer Nature 2021

\begin{abstract}
The education system has been radically transformed by technological impetuses owed to the Fourth Industrial Revolution (4.0). Most recently, developing nations expedited smart education implementation to combat the negative effects COVID19 has on education; thus, presenting managerial issues. A review of the literature on smart education shows that past studies focused primarily on the smart learning environment, substantially ignoring the importance of leadership and human resources capacity in the management of smart education. This study addresses the deficiency observed in the literature as it relates to the key factors that enable success in the management of smart education. The study applied a quantitative approach that derived data from a structured survey of probability simple random sampled Grenadian employees belonging to tertiary education. The Hayes multiple moderated mediation, Model 23, supported by SPSS-PROCESS Macro software was used to examine the study's model. Results showed that human resources capacity has a conditional indirect effect on smart education through the mediating variable of leadership capacity. Additionally, the moderating variables of additional investment in the ' $a$ ' path and student demographics in the ' 6 ' path both displayed significant moderating effects. The findings of the study have provided several valuable insights into the theoretical and practical implications of the influence of leadership and human resources capacity in the implementation of smart education. Therefore, it is recommended, that the soft variables assessed in this paper need to be harnessed accordingly to achieve smart education.
\end{abstract}

Keywords Smart education (SE) · Technology-enhanced learning (TEL) · Human resources capacity $(\mathrm{HRC}) \cdot$ Leadership capacity (LC) - Student demographics (SD) · Additional investments (AdI)

Jonela Carmada Marisa Wilson

jonelawilson@gmail.com

Extended author information available on the last page of the article 


\section{Introduction}

The education system has been fundamentally transformed by modern technologies owed to the Fourth Industrial Revolution (4.0). However, developing nations have been slow to embrace these technologies because of the cost of new systems and entrenched traditional customs. Due to the 2020 pandemic of COVID19, there was an unprecedented upheaval of global education (CGTN, 2020; World Economic Forum, 2020). The effect was the temporary closure of schools and universities in 138 countries plagued by the virus (World Economic Forum, 2020). It is approximated that 1.3 billion learners could not attend school or university in the traditional way (UNESCO, 2020). This effect created a paradigm shift in education systems (Boes et al., 2016; Wairiuko et al., 2018; Zhu et al., 2016) encouraging the provisional move away from the face to face lecture-based approaches to teaching and learning now buttressed by technological pedagogies in a high-tech environment that desired nifty learners (World Economic Forum, 2020).

This new mode of teaching and learning is representative of the smart education (SE) phenomenon. Therefore, SE (Giannakos et al., 2016; OECD, 2016; Zhu et al., 2016a), refers to 'smart technologies' creating intelligent environments stimulated by 'smart pedagogies' to provide personalized learning services that empower learners (Zhu et al., 2016a; Zhu, Yu, et al., 2016). Learners from different nations were empowered by the engagement in instant information sharing and connections across topographies and time zones (Information Polity 21, 2016), via the internet (World Economic Forum, 2020). Their interconnectivity were facilitated through computers and other devices (Internet of Things) such as phones and Tablets (Information Polity 21, 2016; Chatfield \& Reddick, 2018). Learners were also exposed to innovative teaching pedagogies such as Video on Demand (VOD) and Video Conferencing (Bdiwi et al., 2019). Other sophisticated pedagogies used were Learning Management Systems (LMS) such as Exxcess and Moodle, Virtual classrooms, and Augmented Reality.

For the last century, smart education initiatives have been active in developed countries (Budhrani et al., 2018; Lee \& Kim, 2015), such as Malaysia, Singapore, and The United Arab Emirates (UAE). These countries have revamped their education systems to reflect a learning environment that is learner-centric, content-accessible, and ubiquitous (Zhu et al., 2016a). They believe that innovation in education adds value to the improvement of learning outcomes as well as enhances equity in access to education (OECD, 2016). The outcome of innovation in education will be to equip students with $21^{\text {st }}$-century competencies which will allow them to be competitive in the marketplace (Chi et al., 2018; Li et al., 2019).

However, many developing countries such as countries in the small island region of the Caribbean are now seeking to acclimatize technology into the education process (Leem \& Sung, 2019); due to the present COVID-19 status quo. Conversely, the estimated technology consumption among the developing countries population is a mere $2.5 \%$, thus alluding to managerial issues of poor 
infrastructure, weak administration, and unskilled workforce (Kimaro, 2006). According to (Plumb \& Kautz, 2015) as educators hasten to incorporate novel teaching pedagogies into their lessons, challenges of a practical and philosophical nature arise. For example, purchasing a system such as LMS did not translate into a workforce (faculty \& IT staff) capable of immersing themselves into a hightech environment, reinforced by smart pedagogies that preferred technologically savvy learners, and or leadership (administrators) capable of directing this change (Folden, 2012).

Li et al., (2019) cited people, practice, value, and technology as crucial technology adoption factors. Furthermore, (Kimaro, 2006) stated that to adequately prepare for adopting any technology inclusion project, a holistic approach must be fathomed through the identification of main stakeholders (Kats, 2010) such as students, faculty, administrators, and IT staff (Folden, 2012; Steffens, 2008). Most importantly, soft smartness such as human capital and leadership co-exists with hard smartness, such as infrastructural innovation, to efficiently adopt technology in service industries (Boes et al., 2016). Conforming to soft smartness factors needed to adopt SE, an extensive review of literature in SE was conducted. The review showed a steady increase of 35 to 80 per year in SE's published articles between 2016 and 2018 (Singh \& Miah, 2020). Moreover, the majority of the studies focused on evaluating the learning environment (Lai \& Bower, 2019). Consequently, it was apparent that the studies published in SE were seldom considered and omitted from SE's conceptualization external soft smartness variables ( leadership and human resources) that are compulsory to ratify SE's ecosystem (Lai \& Bower, 2019).

Therefore, the study intends to present a platform that will add new knowledge to the SE phenomenon by validating that leadership, human resources capacity, and moderating variables such as additional investment are significant contributors to SE's implementation. Firstly, the study will develop dimensions to measure leadership and human resources capacities. Secondly, the influence of each soft smartness variable on SE's ecosystem will be assessed through a moderated scope. The Actor-Network Theory (ANT) which delineates that a set of actors, specifically people and things, can influence action to facilitate relationships in a phenomenon's ecosystem (Esnault et al., 2006) will be used to buttress the conceptualized presence and participation of leadership and human resources as main variables in the implementation of SE. On the other hand, the basic premise of the Technology Adoption Model (TAM) will be used to assess employees' perception of the usefulness or influence of leadership and human resources capacities in SE's implementation. This quantitative study is reported within the limitation that results reported in this paper can be flawed due to sampling error derivative from the small sample size. However, the paper intends to add knowledge and not to generalize results. Future researchers can supplement the generalization factor to this study by targeting a larger population of educators from several Caribbean countries. Since the present study opened-up dialogue on the fundamental role that external variables such as leadership and human resources capacities acquire in the implementation of SE, developing countries are admonished to harness these variables. 


\section{Literature review and hypotheses}

\subsection{Smart education's background and conceptual frameworks}

As technology use in education gains more prominence there has been a plethora of names or phrases used to describe this phase.. At one point in time and still used in many studies, Technology Enhanced Learning (TEL) was used to describe the implementation and utilization of technology to help learners learn. It focused on the use of media or tools to access learning content so that learners can communicate their inquiry through collaboration. With the development of mobile, TEL took on a new paradigm that encouraged the mobility of the learner, in contrast to its previous static traditional format. Additional advances ushered in an era of ubiquitous learning which incorporated smart devices and intelligent technologies to emphasize learning that can take place anytime and anywhere, subtracting the limitation of time, location or environments. Hence the increased use, discussions, and research surrounding the word 'smart' as it relates to education. According to (Hoel \& Mason, 2018) the educational research community is now routinely using the word 'smart' in many terminologies such as Smart Education, Smart University, Smart Learning, and Smart Learning Environment. The International Association of Smart Learning (IASLE) has considered the previously mentioned terminologies as emerging areas in education. Additionally, the use of the word 'smart' can connote different meanings in each instance.

Fig. 1. Zhu et al.'s conceptual framework of smart education (Zhu et al., 2016a)

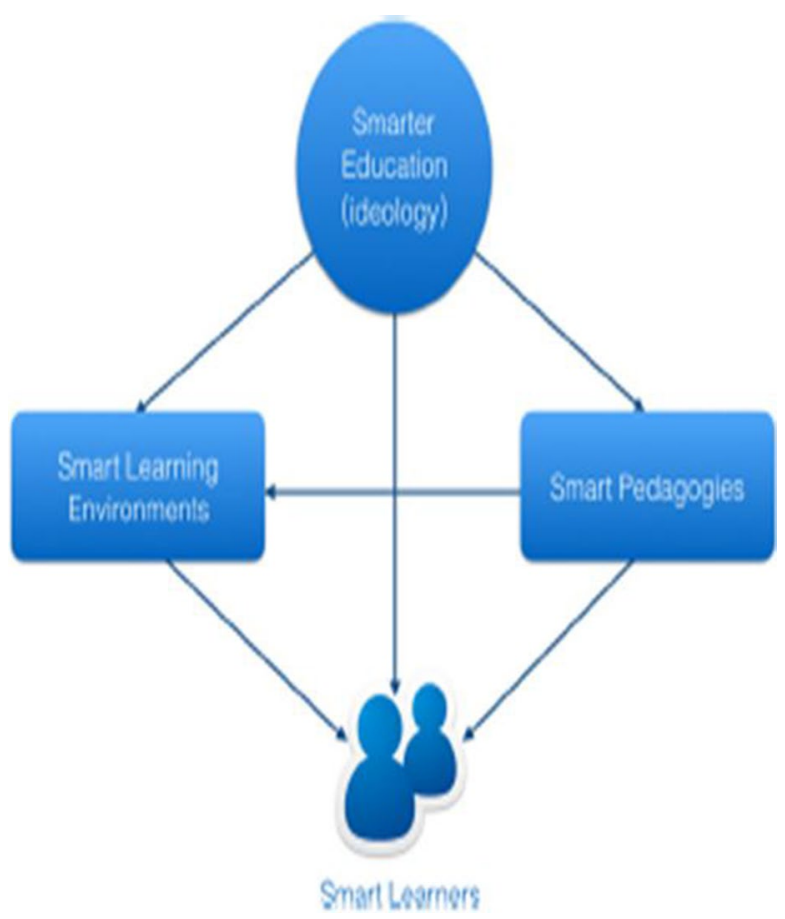


For example, 'smart' in smart education refers to intelligent, personalised, and adaptive; learner refers to wisdom and intelligence, and educational technology refers to achieving its purpose effectively and efficiently. Also 'smart' in hardware denotes portable and affordable smart small devices; and the educational environment speaks of appealing, intellectual, and accessible (Wang et al., 2021).

Studies conducted by (2016b; Zhu et al., 2016a) brought much-desired clarity to the understanding of the smartness phenomenon in education by the organization and conceptualization of smart education into frameworks. The first framework proposed by (Zhu et al., 2016a) (See Fig. 1) has three pivotal elements: the smart learning environment, smart pedagogy (Kiryakova et al., 2018), and the smart learner. In a corresponding study, Zhu et al. (2016b) revised the conceptual framework, including the: teacher's and technology presence (See Fig. 2). This revamped model renamed smart pedagogy to reflect the 'technology' presence and the smart learning environment to the 'teacher's presence.' Therefore, the frameworks created an umbrella that housed three components that traditionally stood on their own to a centralized construct coined SE.

Given the dimensions noted by (Zhu et al., 2016a, 2016b), it has been observed that there is mounting literature presented on the smart learning environment (SLE) and smart pedagogy dimensions. The reviewed literature focused on the historical background of the SLE, environment's design, the technology available, the pedagogy applied, students' behavior, and perception towards such an

Fig. 2. Revamped model of Zhu et al.'s smart education conceptual framework (Zhu et al., 2016b)

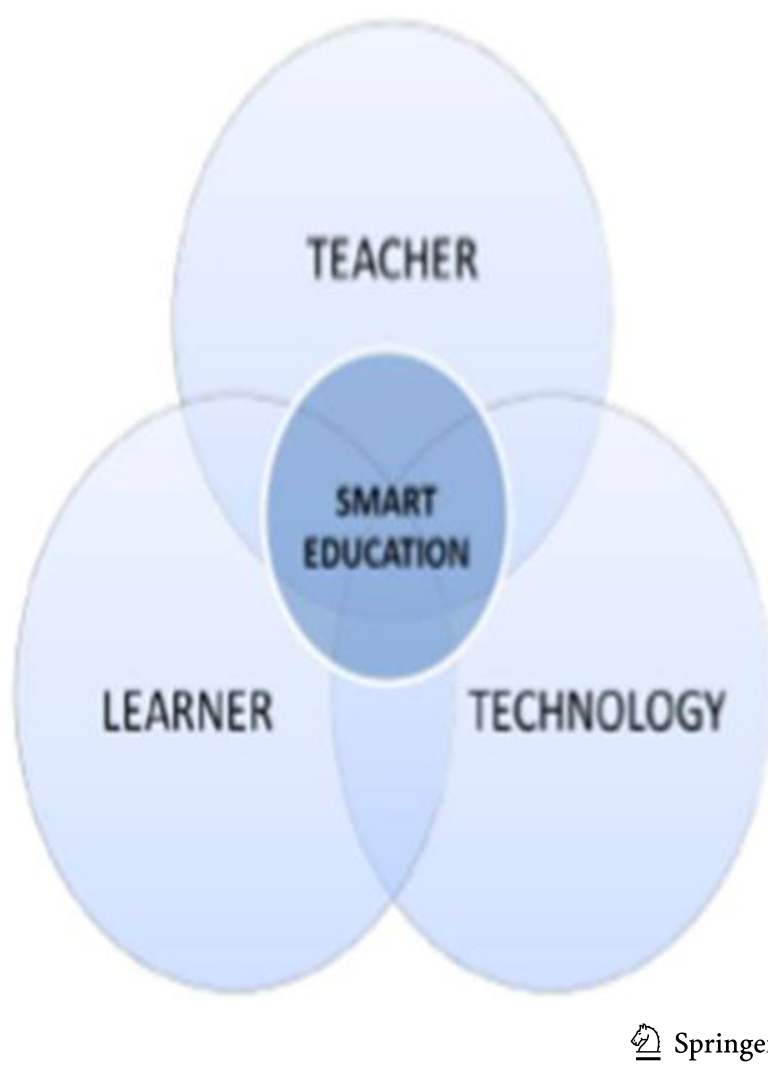


environment (Lai \& Bower, 2019). Firstly, a brief synopsis of the historical backdrop of SLE, shows that it began in the twentieth-century in Educational Psychology with behavioural psychologists who used conditioning to explain behavioural adaptation. The outcome was the development of a learning system that used a mechanical device to store learning management tools. Another learning systems were Computer Assisted Instruction which was developed when computers came on the scene in the 1950s. Following were systems such as Computer Managed Instruction, Instructional Television Fixed Service, and Distance Learning (Kats, 2010). Presently, there are novel learning management systems such as Exxcess and Moodle, and smart pedagogies such as flip classrooms, virtual classrooms, robot learning and augmented reality (Wang et al., 2021).

Secondly, present-day SLE studies provide practical and useful information on how: technology selection can transform courses, technology in education can determine learning styles and technology can transform a school's environment. For example, in a study conducted by (Lin et al., 2018), the intelligent selection of courses for pedagogies in SE was assessed in-depth. This study showed that choosing the accurate courses for the correct pedagogy greatly influenced students' learning. For example, Science courses may merge better with the augmented reality pedagogy that allowed for students to perform simulations. In regards to the use of smart pedagogy to determine learning styles, one study conducted by (Bajaj \& Sharma, 2018) showed how smart education can be created by including artificial intelligence to determine students' learning styles. Here the study focused primarily on student learning and achievement via the SLE. Additionally, (Basset et al., 2018) illustrated in what way IoT could be suitably designed and used within a smart school environment. Finally, (Finogeev et al., 2018) studied the smart learning environment by assessing educational programs and resources' life-cycle (Wang et al., 2021).

It is evident that among the studies conducted, other sides of the SE phenomenon such as the smart learner and the teacher's presence were seldom considered (Uskov et al., 2015). Also, the relationship/s that exist among the dimensions presented in the SE framework is uncertain (Zhu et al., 2016a, 2016b). However, the key gap presented in the literature reviewed is the lack of information regarding the influence of external variables such as leadership and human resources capacities in the implementation of SE. Although SE is expected to produce learning outcomes such as deepened and extended learning experience (IBM Australia, NA); because the managerial aspects of SE are lacking this may affect successful learning outcomes. It is apparent, that as employees become familiar with the SE phenomenon and they seek to incorporate smart pedagogies in a smart learning environment to create smart learners they are faced with many unforeseen challenges. Especially, during this COVID-19 era, they are faced with challenges such as lack of computer competency (Momani et al., 2016), lack of a clear vision from leadership (Momani et al., 2016), and lack of training (Plumb \& Kautz, 2015). Consequently, (Lim et al., 2011) proposed that vision \& philosophy, professional learning, ICT plan, infrastructure resources, and communication \& partnership should be at the forefront of strategic planning of capacity building for technology in education. These challenges confirm the need for a holistic approach to SE's adoption that demonstrates the importance 
of leadership and human resources as precursors to SE's implementation. Without an intentional observation of these precursors, there will be a continued hasty adoption of SE and a glaring persistence of managerial catastrophes. Therefore, to honein on the deficiency detected in the literature this paper aims to use the subsequent theories (Actor-Network Theory \& Technology Adoption Model) to support the claim for the inclusion of leadership and human resources capacities as predecessors to SE's enactment (Wang et al., 2021).

\subsection{Theoretical background: Actor-network theory \& technology adoption model}

When considering the adoption of technology, theories such as the Technology Adoption Model (TAM), Theory of Task-Technology Fit (TTF), and Actor-Network Theory (Esnault et al., 2006; Lai, 2017) have been utilized. However, to build a framework that incorporates the managerial aspects into SE, the Actor-Network Theory will be used because of its broad uptake in technology implementation in education (Fenwick \& Edwards, 2010). Developed in the 1980s, the theory observes the relationship between human and non-human objects within a given scenario (Seuwou et al., 2017). One of the main instigators of the ANT states that the ANT “ Tells stories about how relations assemble or don't [by providing a sensibility to the messy practices of relationality and materiality of the world" (Law, 2007, p.7). ANT postulates that a participatory nature is needed to adopt novel technology (Esnault et al., 2006). Consequently, "for any actor to act, many others must act as well" (Bencherki, 2017, p.1). In other words, a multitude of people (leadership \& human resources) and things (additional investment $\&$ student demographics) share in actions that may be carried out intentionally or unintentionally. Actors can be individual or collective, human or non-human, capable of acting and interacting to bring about their influence (heterogeneity) (Bencherki, 2017). Therefore, according to (Latour, 1996, p.369) " an actant can literally be anything, provided it is granted to be the source of an action". As such, ANT maintains a socio-technical stance as it affirms that humans and technology are equal actors in an ecosystem (Boes et al., 2016). Additionally, the action of humans is not only human but can unfold or be delegated into networks with multiple configuration (Callon, 1999).

In light of the conceptualiation of the ANT, past studies were able to use the ANT to form a theoretical foundation for their studies. For example, Creswell et al., 2010 used the ANT to inform and conceptualise the implementation of IT in the healthcare setting especially as there is an increased presence of computerisation in modern healthcare. Costa \& Cunha, 2009 highlighted that the modern practice of stakeholders creating innovative business models virtually has posed a number of unfeasible challenges in the physical world. To address this problem the authors applied the ANT to provide insights into the socio-technical settings of where humans and non-human agents interact by describing how the ANT principles can be embedded in the approach for complex business models. Finally, Choi et al., 2018 applied the ANT in their study by using the four steps of translation in investigating the formation and variation of various actors in the 
development of graphene R\&D policies in Korea. These previous studies provide a strong foundation for the use of the ANT in this present study. Therefore, the ANT will be used to buttress the paper's claim that people such as leadership capacity and human resources capacities are pivotal variables in the implementation of SE.

The Technology Adoption Model (TAM) was introduced by Fred Davis in 1986. Davis (1985) emphasized that the advancement in computer technology contributed tremendously in making powerful end-user systems economically attractive. Additionally, system designers have communicated that testing system prototypes with actual prospective users is an effective way to evaluate and refine the design proposed. When user acceptance is utilised in testing, and thereafter generates success in explaining the perceive acceptance of users, it provides valuable information for system designers and implementators. As such the TAM was conceptualised to specifically tailor for modelling users' acceptance of information systems or technologies by explaining the general determinants of computer acceptance that led to explaining user's behaviour towards these technologies (Lai, 2017). Therefore, the basic TAM model tested two (2) specific beliefs: Perceived Usefulness and Perceived Ease of Use. Perceived Usefulness has been described as the potential user's belief that the use of a particular system will improve his/her actions. On the other hand, Perceived Ease of Use was defined as the degree to which the potential user expects the target system to be effortless. However, the general belief of a user in regards to a system can be influenced by external variables in TAM (Lai, 2017). For this paper, leadership capacity and human resources capacity will be assessed as external variables that can affect the implementation of the SE system. The belief of Perceived Usefulness will be used to evaluate employees' perception of the influence of leadership and human resources capacities on the implementation of SE.

The TAM formed the theoretical foundation for many studies seeking to evaluate users' perception of technology. For example, Liao et al. (2018) used TAM in their study to explore students' behavioural intention in technological colleges and universities when using web-based performance assessment system as a tool to evaluate their technical proficiency in e-book production. The authors concluded their research by confirming that TAM can be used to explain users' willingness to adopt a web-based assessment system. In the Koul and Eydgahi (2018) study, the two main beliefs of TAM enabled the researchers to examine the relationship between perceived usefulness of driverless car technology and the perceived ease of use of driverless car technology. The study found significant positive relationships between the latter variables mentioned. Finally, Hubert et al. (2018) combined TAM, Innovation Diffusion Theory and Risk Theory in their study to address the smart home application context. The authors found that each theory provided unique insights into the understanding of technology acceptance in the application of smart homes. The previous studies demonstrate TAM's popularity in building theoretical foundations for papers evaluating technology use from the end-users perspectives. However, for the purpose of this study TAM will be administered through novel arrangements of the variablesstudied in this paper. As such, instead of the external variables acting on the belief of Perceived Usefulness, the belief of Perceived Usefulness will be acting 


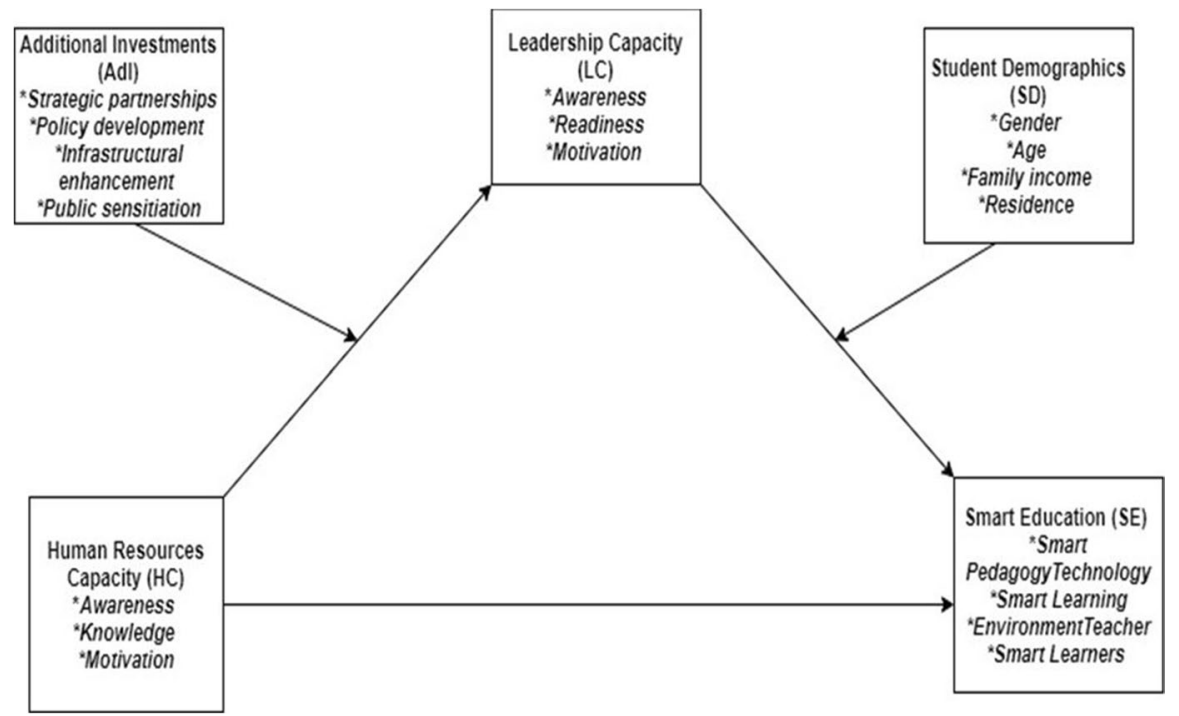

Fig.3. Proposed conceptual framework of the measurement of variables in SE's ecosystem. Notes: a, is the effect of human resources capacity on leadership capacity; 6 , is the effect of leadership capacity on smart education; $c$, is the direct effect of human resource capacity on smart education.

on the external variables highlighted. In so doing, ANT and TAM are used to offer the conceptual multiple moderated mediation models presented in Fig. 3 \& Fig. 4.

\subsection{From human resources capacity to SE}

In line with the main premise of the ANT, it can be stated that one of the most imperative actor that contributes to the formation of a phenomenon's ecosystem is human resources. For this paper, human resources capacity will be examined.

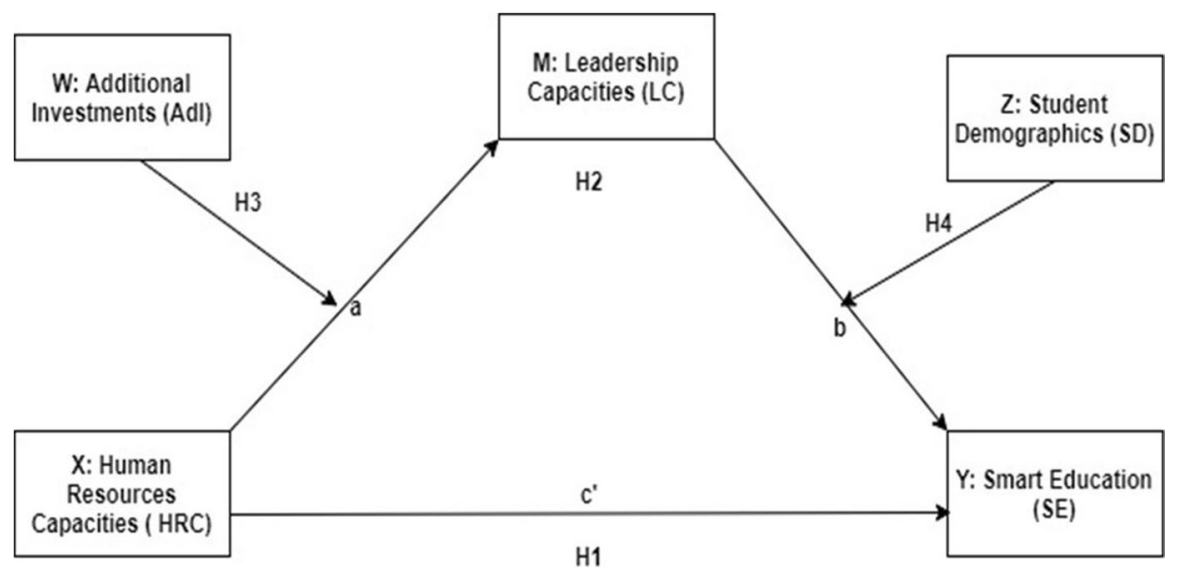

Fig. 4. Multiple moderated mediation using the mediating effect of leadership Capacity on the relationship between human resource capacity and smart education 
Therefore, human resources capacity building is "the development of knowledge, skills, empowerment, and attitudes in individuals and groups of people relevant in design, development, management, and maintenance of institutional and operational infrastructures and processes that are locally meaningful" (Yamoah, 2014, pp. 4). This paper intends to look at the capacity of human resources by firstly creating dimensions through using three (3) prominent theories of motivation. They are the Process Theories of motivation: Valence-Instrumentality Expectancy Theory (awareness); and Goal setting theory (readiness/knowledge); and the Content Theory of Motivator-Hygiene (Two-Factor) Theory (motivation). Studies have shown that these theories have a great impact on employee's job satisfaction and work performance. The presupposition for using these theories was to show that human resources that are built on these capacities are more likely to perform or gravitate towards a new project as has been proven in ample researches (Schultz \& Schultz, 2010).

Consequently, the human resources prominence in 'smartness' initiatives are emphasized in areas such as e-government (Alketbi, 2018; Wairiuko et al., 2018), smart tourism (Boes et al., 2016), and smart government (Al-Jenaibi, 2016). For example, besides having actionable ICT facilities to bring smart governance into action, the interaction of human skills (Scholl \& Scholl, 2014), such as attitudes, motivations, and Knowledge (Garcia et al., 2016; Smith, 2005), were cited as requirements. In separate studies, (Wairiuko et al., 2018) \& (Alketbi, 2018) evaluated the importance of human resources capacity in e-government implementation in Kenya and The United Arab Emirates. Results showed a strong positive association between human resources capacity and the adoption of e-government.

Hence, many organizations spend considerable resources on building employees' capacities (Abdullah, 2009; Yamoah, 2014). Therefore, the nature and experience of the smart pedagogy used in SE are more so determined by human resources (instructor and IT staff) than anyone else. Accordingly, human resources are seen as the arbitrators of whether students will participate in SE activities or not. Institutions in developed countries have taken a bottomup approach to SE's implementation, thus choosing the smart pedagogy based on the user's demands since users have a concrete will and request to use the selected pedagogy. The Technische Universitat Braunsch Weig in Germany applied a bottom-up approach to implement LMS. Other universities in Germany, such as Universat Osnabruck, employed the top-down approach, whereas Leibniz Universitat Hannover applied an equal mixture of a bottom-up and topdown approach (Folden, 2012). Despite the approach, it remains that although technology in education may enable change at an increased rate, transforming the classroom dramatically depends on human resources knowledge, attitudes, and behaviours (Price, 2015). According to (Boes et al., 2016) only in a relationship with human agency, social structure and organization does technology fulfill functions. Therefore, the ultimate question is how do employees perceive the influence of human resources capacity on SE's implementation? Therefore, the first (1) hypothesis is proposed:

H1: HRC has a positive effect on smart education 


\subsection{Leadership capacity as a mediating factor}

Building from the ANT, the other actor that is fundamental to the enacting of a phenomenon is leadership. The purpose of this study is not to assess the best leadership style which will best influence SE's implementation; but, rather develop leadership capacities. Therefore, leadership capacity means "the broad-based, skillful participation in the work of leadership; and a way of understanding sustainable school improvement" (Lambert, n.d., pp.1). As with human resources capacity, the dimensions of leadership capacity have been formulated using the same Process and Content theories. This has been done to demonstrate what leadership should possess when building the capacity of human resources as well as the areas they should indoctrinate in human resources. Therefore, studies such as the adoption of e-government in Dubai concluded that [leadership] has a significant, strong positive correlation on the implementation of e-government (Alketbi, 2018). Similarly, Kakabadse et al. (2014) emphasized visionary leadership as a necessary facet in smart government transformation. Therefore, leadership in smart transformation: 1. creates an avenue for articulating change (awareness), 2. The pace of transformation is understood by stakeholders (motivation), and 3. Sufficient preparation for efficient strategy execution (readiness) is made (Kakabadse et al., 2014). Thus, the smart leader incorporates others in the co-creating of vision by engaging and motivating people to co-create a smart future (Lee \& Trimi, 2016).

Leadership support, whether at a macro (national) or meso (administrators) levels, is crucial since they are the gatekeepers of innovative technology and pedagogical practices (Price, 2015). It is the leadership's responsibility to focus on an institution's future needs by establishing strategic plans for technological innovation. Therefore, management needs to align SE pedagogies with the department and university curriculum. Additionally, motivation and incentives generation are also essential leadership tasks that will encourage human resources to accept and integrate technology in teaching (Folden, 2012). A focus on leadership stresses a topdown approach for administrations to push the integration of smart pedagogies into the university so that human resources have to use the pedagogy for some processes. Institutions such as the University of Genova have adopted this approach but with unsuccessful results. Other schools such as the Universitat Osnabruck experienced success with the top-down approach. For some universities, a bottom-up approach was pragmatic. However, (Boes et al., 2016) confirms that it is leadership that needs to create and ensure that innovation is being fostered within an environment. This provides good stead to assess how employees perceive the influence of leadership capacity in SE's implementation. Therefore, the second (2) hypothesis is proposed:

H2: HRC has an indirect effect on SE through leadership capacity.

\subsection{The moderating role of additional investments}

To fully experience technology's benefits in education, systems such as computer and software infrastructures must be available. According to the ANT, the 
later examples can be referred to as things needed to congeal with leadership and human resources capacities to achieve the SE phenomenon. Therefore, tools \& environment as a perceived barrier to technology adoption (Park \& Ertmer, 2008; D. Capital Partners, 2013) is revealed in lack of equipment/resources, classroom conditions \& constraints, and IT technical support (Momani et al., 2016; Plumb $\&$ Kaultz, 2015). Therefore, countries or administrations wishing to adopt educational, technological platforms may fund or engage in strategic partnerships to help access the best and appropriate innovative infrastructures. Additionally, there needs to be strategic policy development that will identify hindrances that will affect HRC's full impact in SE implementation. From this exploration, appropriate investments that can combat these hindrances can be suitably crafted. Researchers in other smartness concepts like smart cities highlighted several moderating investment initiatives. They are policy development (OECD, 2016; Yaghi \& Al-Jenaibi, 2018), Smart strategic partnerships (Leahy et al., 2016), Innovative infrastructure (Boes et al., 2016; Leahy et al., 2016), and public sensitization (Kakabadse et al., 2014) as investments that can ease the burden of technology adoption. Therefore, the third (3) hypothesis is proposed:

H3: Additional investments to combat hindrances (barriers) moderate the relationship between HRC and leadership

\subsection{The moderating role of student demographics}

There are several positive outcomes, such as the decrease of cognitive load to be attained from the adoption of SE (Zhu, Sun, et al., 2016; Zhu, Yu, et al., 2016). However, Leahy et al. (2016) allude to the equitable access to technology as a significant pitfall of SE implementation. According to (Shah \& Shah, 2018; and Casanova et al., 2005), socio-demographic variables have a strong correlation with student success. As such, student demographics can also be considered as one of those things needed to coagulate with LC and HRC for SE's successful implementation to be achieved. Accordingly, (Hanafi \& Noor, 2016) concluded in their research that age, gender, parents' income, and location have a significant positive relationship with academic achievement. Therefore, applying similar demographic principles stimulates concerns that student demographics such as gender, family's income, and residence can affect learners' access to the tools required to participate in SE adequately. Therefore, the fourth (4) hypothesis is proposed:

H4: Student demographics moderate the relationship between leadership capacity and $S E$

In summary, Fig. 3 gives an overview of how the assigned variables are measured and interact with each other is presented. Figure 4 shows a multiple moderated mediation model, where leadership capacity mediates the relationship between HRC and SE, with Additional Investments moderating the relationship between HRC and LC, and Student Demographics moderating the relationship between LC and SE. Overall, the model represents a socio-technical ecosystem for SE's efficient implementation. 


\section{Methodology and material}

\subsection{Data collection \& sampling procedures}

This study adopted a quantitative approach that allowed for verification of the proposed conceptual model. Several steps were used in data collection to meet the intended purpose (Jonker \& Pennink, 2010; Saunders et al., 2009). The Caribbean island of Grenada was selected because of convenience, as well as it is among the developing small island nations making steady progress in e-government adoption and e-participation (The United Nations, 2018; Government of Grenada, 2018; Government of Grenada, 2019). Due to the novelty of the SE phenomenon and the lack of literature in regards to leadership capacity and human resources capacity's influence in SE's implementation it was essential to develop a structured questionnaire. This questionnaire was required to be a tool that allowed employees to share their perception of the influence of leadership, human resources capacities, and moderating variables in SE's implementation. Additionally, the statements used in the questionnaire had to reflect a keen understanding of the culture and the status quo of technology in education as it relates to Grenada (Wang et al., 2021).

Bearing in mind the intent of the survey, officials from Grenada's Ministry of Education (MOE) were approached to secure permission in executing the study's methodology. Therefore, two (2) groups of ten (10) experts in the field of education were recruited, to research, develop a structured questionnaire, and pilot test the survey. This was done to ensure the content validity of the questionnaire instrument. Therefore, the experts will be able to review the items and comment on whether the items cover a representative sample of the behavior domain. The experts were chosen through the probability simple random sampling where The Chief of Education in Grenada's MOE provided a list of fifty (50) experts qualified in the area of Education Administration. To limit the chances of bias the names of the fifty (50) experts were firstly coded into four-digit numerals, for example, 1111, 2222 (Wang et al., 2021).

These codes were written on small pieces of clear papers, folded, and then dropped into a raffle bag for random selection. Two (2) raffle draws were performed where the first raffle derived ten (10) experts ( 5 males; 5 females) for research and questionnaire development. The second raffle derived another ten (10) experts (7 males; 3 females) for pilot testing of the questionnaire. The probability of selection for Expert Group A was 2.0percent $(10 / 50=0.2)$; whereas, the probability of selection for Expert Group B was 2.5 percent $(10 / 40=0.25)$. The randomly selected participants were contacted using email with a contract for terms of participation attached. A follow-up phone call was done to officially inform experts of their selection and to confirm their participation. All selected experts confirmed their participation by returning the signed contract via email. The first group of experts (Expert Group A) met for four (4) weeks, with three (3) one (1) hour sessions held per week. The first two (2) weeks of sessions were used to present research findings, while the other two (2) weeks were used for questionnaire development and confirmation of statements for variables' Likert scale (Wang et al., 2021). 
After an extensive literature review on technology in education, leadership, and HR's influence on 'smartness' phenomenons such as e-government the questionnaire was finalized. For the variables of leadership and human resources capacities, the experts agreed on modifying the original statements from (Alketbi, 2018) study which assessed human resources capacity and top management as success factors in e-government's implementation. These statements were grouped into three dimensions which followed the Process Theories of motivation: Valence-Instrumentality Expectancy Theory (Awareness); and Goal setting theory (readiness/knowledge). The statements for the dimension of motivation for both leadership and human resources capacities followed the Content Theory of Motivator-Hygiene (Two-Factor) Theory. The statements were only formed to assess the Motivator aspect of the theory. It considered specifically facets outside of awareness and readiness such as recognition. The statements for both moderating variables were formulated mainly from literature from Kakabadse et al., 2014; Shah and Shah (2018); \& Casanova et al. (2005).

The questionnaire was then pilot tested among the second group of experts (Expert Group B) for two weeks with two (2) one (1) hour sessions per week. During the first week of testing the experts highlighted discrepancies with two (2) statements from the variable additional investment and one (1) statement from the variable student demographics. With the refinement of these statements and agreement amongst both groups of experts, the next step was engaged. Grenada's Ministry of Education was once again contacted to obtain authorization to distribute questionnaires via three of their social media platforms (Facebook Page \& Messenger, WhatsApp Group for principals \& WhatsApp Group for teachers). These platforms had a member base of teachers from primary, secondary, and tertiary institutions. The questionnaire was arranged in googleforms.com, then the URL was shared with senior staff at the Ministry of Education Grenada to upload to their social media platform and email to members in their friends' list. The senior staff uploaded and emailed URL to contacts for three (3) weeks (Wang et al., 2021).

Taking advantage of a probability simple random sampling, a total of six hundred (600) respondents were approached via the MOE's three social media platforms. The respondents were tertiary level educators who were either faculty members, researchers, professors, or relevant individuals with administrative responsibilities in one of the three tertiary institutions located on the island. However, out of the six hundred (600) respondents approached, three hundred and fifty five (355) questionnaires were received and filled online, that is 59.2 percent. Out of three hundred and fifty five (355) questionnaires, three hundred and forty nine $(\mathbf{n}=\mathbf{3 4 9})$ were found correct, making 98.3percent fit to proceed to analysis. Out of three hundred and forty-nine (349) respondents, 32.3\% were male and $67.7 \%$ were female. The highest age range of participants was 18- 25 (31.3\%) years. Most respondents' highest education level was an Associate Degree (35.4\%). The majority of the respondents were from the public sector. Table 1 provides further demographic information on the targeted sample. Therefore, a diverse and large enough sample enabled this quantitative research design to allow for a moderated mediation and Correlation testing using SPSS Process Macro (Wang et al., 2021). 
Table 1 Demographic Descriptive Results of Respondents

\begin{tabular}{|c|c|c|}
\hline Variables & Frequency & Percent \\
\hline \multicolumn{3}{|l|}{ Gender } \\
\hline Female & 113 & 32.3 \\
\hline Male & 236 & 67.7 \\
\hline \multicolumn{3}{|l|}{ Age Range } \\
\hline $18-25$ & 109 & 31.3 \\
\hline $25-30$ & 58 & 16.7 \\
\hline $31-35$ & 67 & 19.2 \\
\hline $36-40$ & 37 & 10.6 \\
\hline $41-45$ & 23 & 6.6 \\
\hline $46-50$ & 23 & 6.6 \\
\hline $50+$ & 32 & 9.1 \\
\hline \multicolumn{3}{|l|}{ Qualification Level } \\
\hline Associate Degree & 124 & 35.4 \\
\hline Bachelor & 97 & 27.8 \\
\hline $\mathrm{CoC}$ & 23 & 6.6 \\
\hline Diploma & 23 & 6.6 \\
\hline Masters & 72 & 20.7 \\
\hline $\mathrm{PhD}$ & 11 & 3.0 \\
\hline \multicolumn{3}{|l|}{ Sector Employed } \\
\hline Private & 124 & 35.4 \\
\hline Public & 175 & 50.0 \\
\hline Self-employment & 51 & 14.5 \\
\hline Total & 349 & 100.0 \\
\hline
\end{tabular}

CoC Certificate of Completion

\subsection{Measures}

The description of standards used in a study must be specified once the discussion of sampling and data collection have been presented (Kotze, 2007). Therefore, a Likert Scale for leadership capacity, human resources capacity, smart education, additional investment, and student demographics were developed. The statements used in the Likert Scale for variables of leadership and human resources capacities were adopted from a study that assessed human resources capacity and top management as success factors in e-government's implementation in Dubai's smart government departments. The statements for other variables were derived through research findings, followed by refinement of statements by experts. Aligning with theories of motivation and the definition of leadership and human resource capacities, three tenets were developed for each variable. All scale points for the set of statements for all variables were made up of equal favorable and unfavorable statements. These statements were concerning respondents' attitude to a specific object labeled, ranging from 1 (strongly disagree) to 5 (strongly agree) (Olaniyi, 2019). The tenets for constructing human resources capacity and 
leadership capacity each bore at least seven (7) to nine (9) statements; whereas the statements for other variables ranged from four (4) to five (5).

\section{Reliability \& validity tests}

The preliminary analysis conducted included several exploratory inquiries (Saunders et al., 2009). The internal consistency reliability of the Likert Scale was calculated and reported through the investigation of the Cronbach Alpha (Kumar, 2011; Olaniyi, 2019). The value of the Cronbach Alpha usually ranges between 0.00 and 1.00. Therefore, discriminant validity for the HRC, LC, SE, AdI, and SD scales (See Table 2) were supported by an exploratory factor analysis, which revealed that each item loaded on its respective factor was significant. The accepted Cronbach Alpha demonstrates that all Likert scales are reliable for moderated mediation analysis.

Other than Content Validity, Internal Validity was also assessed to estimate the degree to which conclusions about the causes of relations are likely to be true. Especially, because of the measures used, the setting of the research, and the research design as a whole. The Pearson Correlation Test performed in SPSS showed significant operationalization for all the measures examined in this study. An excerpt of the results of the Correlation Test for some of the variables are presented in the Appendix. Additionally, exploratory data analysis was conducted by completing data cleaning, which ensured the data file (Hayes, 2013).

\subsection{Multiple moderated mediation model}

The theoretical model illustrated in Fig. 4 was tested by running a conditional multiple moderated mediation analysis using PROCESS macro (3.5) for SPSS (IBM, 25.0) with the mean composite scores on the items for each construct (Hayes, 2013). The moderated mediation test was conducted under several statistical assumptions. For example, co-linearity and homoscedasticity were employed. The analysis assessed: the effects of HRC on SE's implementation (both directly and indirectly, through LC); the impact of HRC on LC (as moderated by Additional Investment); and the effect of LC on SE (as moderated by Student Demographics). The estimate of the conditional indirect effect of HRC on SE through LC combined mediation and moderation was completed (Model 21 by Hayes, 2013; see Fig. 4). Since the tenets of HRC and LC are divided into three, the Process Macro test was conducted three times to consider each construct that was in the path of moderation and mediation. The evaluated means of 10,000 bootstrap samples that created bias-corrected confidence intervals (CI; 95\%) were used to show the statistical significance of the direct and indirect effects. According to Hayes (2013), the modern standard for testing indirect effects is the bootstrapped confidence interval (Hayes, 2013). 


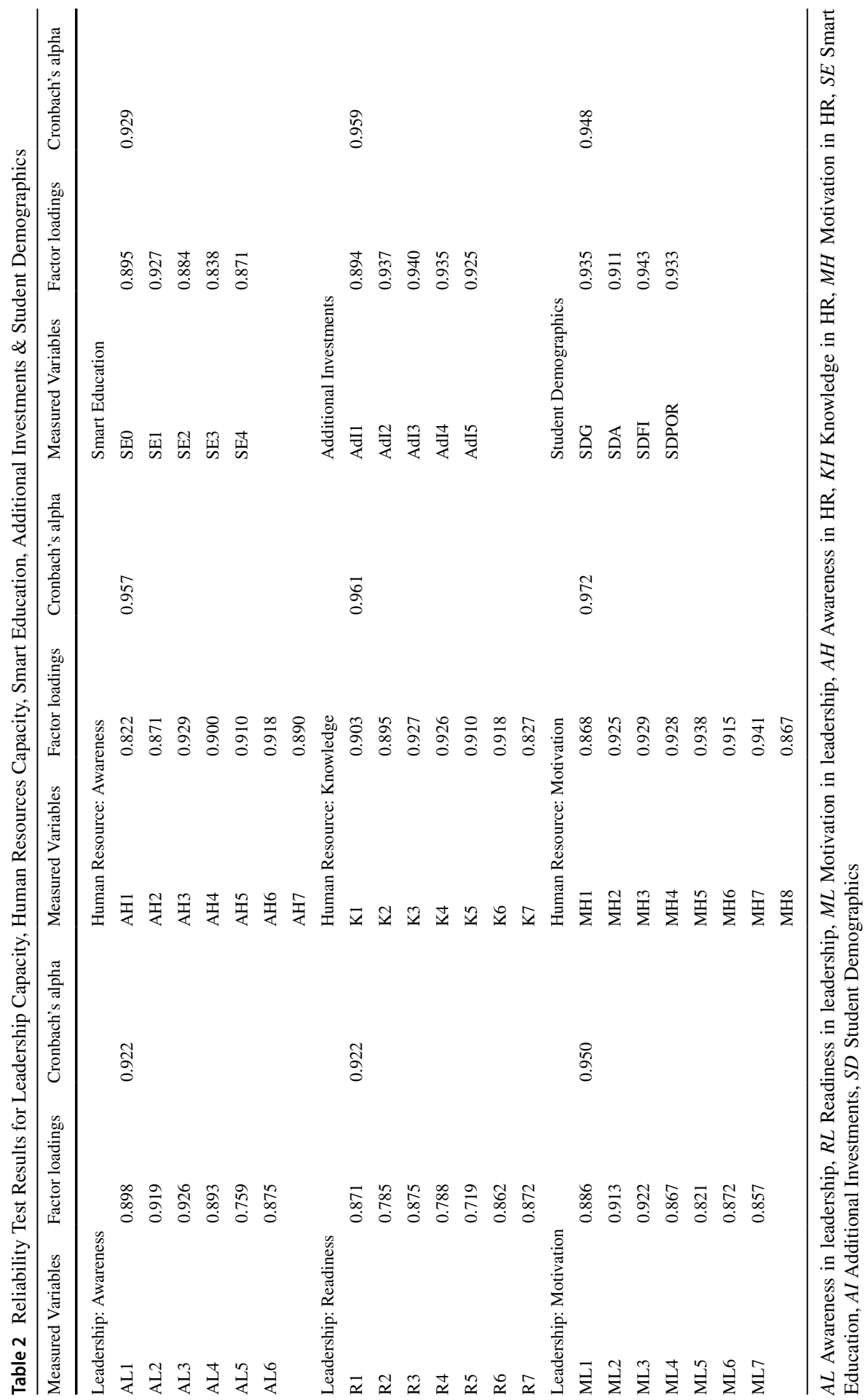




\section{Results}

\subsection{Hypotheses testing}

\section{H1: HRC has a positive effect on smart education}

The first hypothesis offered that human resources capacity would have a positive effect on smart education. This hypothesis will be accepted since there is not sufficient bootstrap confidence to reject the claim hypothesized. The bootstrap confidence interval in the direct or ć pathway from HRC to SE had non-significant bootstrap results in Table 3 through the three HRC tenets of motivation (LLCI $=-0.6306$, $\mathrm{ULCI}=0.4719)$, knowledge $(\mathrm{LLCI}=-0.5783$, $\mathrm{ULCI}=0.4591)$, and awareness $(\mathrm{LLCI}=-0.1999, \mathrm{ULCI}=0.7518)$. This claim is further supported by positive correlation coefficients presented in Table 5 below with awareness (AHR 0.063); Knowledge (Know 0.038), and motivation (MHR 0.039), respectfully.

H2: HRC has an indirect effect on SE through leadership capacity

Likewise, as depicted in Table 4, it was hypothesized that HRC has an indirect effect on SE through leadership capacity. Results support the hypothesis (H2) as bootstrap confidence intervals satisfy the significant condition. For instance, the relationship between the construct of awareness ( $\mathrm{LLCI}=0.0225, \mathrm{ULCI}=0.0437$ ) and motivation (LLCI $=0.0140, \mathrm{ULCI}=0.0920)$ in human resource and SE is significantly mediated by the leadership construct, readiness. The leadership construct of awareness also presented significant bootstrap confidence intervals for the three HRC constructs in mediating the relationship between HRC and SE. Moreover, there were significant bootstrap confidence intervals for the LC tenet of motivation in mediating the relationship between HRC and SE.

The conditional indirect mediating effect of LC on the influence of HRC on SE was also supported through correlation testing. However, testing all significant correlations listed in Table 5 would go beyond this paper's scope. Thus, only the relationships involving the hypothesized variables are reported. The correlation coefficients and significant levels show that HRC is positively related to leadership capacity. For instance, correlation coefficients show that all HRC tenets (Awareness, Knowledge, and Motivation) led to higher leadership capacities (Readiness, Awareness, and Motivation). For example, the Readiness (Re) tenet of leadership led to the following results from HRC (Awareness $\beta=0.543$; $p<0.001$; Knowledge $\beta=0.498 ; p<0.001$; Motivation $\beta=0.535 ; p<0.001)$. For the Awareness (AWE) tenets' of leadership (Awareness $\beta=0.592 ; p<0.001$; Knowledge $\beta=0.600 ; p<0.001$; Motivation $\beta=0.610 ; p<0.001)$. Likewise, for the motivation (Mo) tenets (Awareness $\beta=0.517 ; p<0.001$; Knowledge

Table 3 The direct effect of $\mathrm{X}$ (HRC) on Y (SE)

\begin{tabular}{lllllll}
\hline X & \multicolumn{1}{l}{ Coeff } & SE & \multicolumn{1}{l}{$T$} & $p$ & \multicolumn{1}{l}{ LLCI } & ULCI \\
\hline MHR & -0.0794 & 0.2812 & -0.2821 & 0.7778 & -0.6306 & 0.4719 \\
AHR & 0.2759 & 0.2428 & 1.1365 & 0.2557 & -0.1999 & 0.7518 \\
Know & -0.0596 & 0.2646 & -0.2253 & 0.8217 & -0.5783 & 0.4591 \\
\hline
\end{tabular}

Coeff coefficient; SE standard error, $p<0.05$ (significant) LLCI lower limit confidence interval; $U L C I$ upper-limit confidence interval 
Table 4 Conditional Indirect Effects of HRC on SE via (AI) HIF as Moderator

\begin{tabular}{llllll}
\hline Mediator & HRC & Coeff & BootSE & LLCI & ULCI \\
\hline Readiness & AHR & 0.0029 & 0.0579 & 0.0225 & 0.0437 \\
& Know & 0.0016 & 0.0277 & 0.0170 & 0.0324 \\
& MHR & 0.0107 & 0.0294 & 0.0140 & 0.0920 \\
Awareness & AHR & 0.0009 & 0.0354 & 0.0174 & 0.0395 \\
& Know & 0.0009 & 0.0275 & 0.0150 & 0.0392 \\
Motivation & AHR & 0.0005 & 0.0139 & 0.0225 & 0.0275 \\
& Know & 0.0000 & 0.0243 & 0.0181 & 0.0283 \\
& MHR & 0.0005 & 0.0153 & 0.0204 & 0.0277 \\
\hline
\end{tabular}

Coeff coefficient; SE standard error; $L L C I$ lower limit confidence interval; $U L C I$ upper-limit confidence interval

$\beta=0.576 ; p<0.001 ;$ Motivation $\beta=0.590 ; p<0.001)$. Additionally, results in Table 5 below present correlation coefficients and significance level, which confirms that leadership capacity is positively related to SE (Re.063, AWE.081, and Mo.002).

H3 Additional investments to combat hindrances moderate the relationship between HRC and leadership

Below Table 6 illustrates that AdI (HIF) moderates the relationship between all HRC and LC constructs significantly. The coefficients and bootstrap confidence interval show that through the LC construct of readiness as moderated by AdI (HIF), the HRC constructs of Awareness: $\beta=0.5061 ; p<0.00$; Knowledge: $\beta=0.3411 ; p<0.0001$; and Motivation: $\beta=0.3984 ; p<0.000$ ) have been significantly moderated. Similarly, through the LC construct of awareness, HRC constructs (Awareness: $\beta=0.5271 ; p<0.00$; Knowledge: $\beta=0.5271 ; p<0.0000$; and Motivation: $\beta=0.5603$; $p<0.000$ ) were moderated by AdI (HIF). Finally,

Table 5 Correlations Matrix

\begin{tabular}{llllllllll}
\hline & SE & Re & AWE & Mo & AHR & Know & MHR & SD & AdI(HIF) \\
\hline SE & 1 & & & & & & & & \\
Re & 0.063 & 1 & & & & & & & \\
AWE & 0.081 & $0.809^{* *}$ & 1 & & & & & & \\
Mo & 0.002 & $0.769^{* *}$ & $0.873^{* *}$ & 1 & & & & & \\
AHR & 0.063 & $0.543^{* *}$ & $0.592^{* *}$ & $0.517^{* *}$ & 1 & & & & \\
Know & 0.038 & $0.498^{* *}$ & $0.600^{* *}$ & $0.576^{* *}$ & $0.687^{* *}$ & 1 & & \\
MHR & 0.039 & $0.535^{* *}$ & $0.610^{* *}$ & $0.590^{* *}$ & $0.752^{* *}$ & $0.875^{* *}$ & 1 & & \\
SD & -0.033 & -0.026 & 0.009 & 0.018 & 0.094 & 0.016 & 0.009 & 1 & \\
AI(HIF) & -0.026 & -0.104 & -0.064 & -0.046 & -0.078 & 0.002 & -0.034 & $0.163^{*}$ & 1 \\
\hline
\end{tabular}

$S E$ smart education; $R e$ readiness in leadership; $A W E$ awareness in leadership; $M O$ motivation in leadership; AHR awareness in HR; Know-knowledge in HR; $M H R$ motivation in HR; SD student demographics; $A I(H I F)$ additional investment for hindrances

$* *$ Correlation is significant at the 0.01 level (2-tailed) 
Table 6 Influence of AI (HIF) as a moderator on $\mathrm{SE}$

\begin{tabular}{lllllll}
\hline \multicolumn{7}{l}{ Mediator Readiness } \\
\hline HRC & Coeff & SE & $T$ & $p$-value & LLCI & ULCI \\
\hline AHR & 0.5061 & 0.0732 & 6.9177 & 0.0000 & 0.3615 & 0.6506 \\
Know & 0.3411 & 0.0843 & 4.0471 & 0.0001 & 0.1746 & 0.5076 \\
MHR & 0.3984 & 0.0813 & 4.8996 & 0.0000 & 0.2378 & 0.5590 \\
Mediator Awareness & & & & \\
AHR & 0.5271 & 0.0842 & 6.2596 & 0.0000 & 0.3608 & 0.6934 \\
Know & 0.5271 & 0.0842 & 6.2596 & 0.0000 & 0.3608 & 0.6934 \\
MHR & 0.5603 & 0.0805 & 6.9643 & 0.0000 & 0.4014 & 0.7193 \\
Mediator Motivation & & & & \\
AHR & 0.5042 & 0.0835 & 6.0351 & 0.0000 & 0.3391 & 0.6692 \\
Know & 0.5172 & 0.0911 & 5.6775 & 0.0000 & 0.3372 & 0.6971 \\
MHR & 0.5305 & 0.0864 & 6.1371 & 0.0000 & 0.3597 & 0.7013 \\
\hline
\end{tabular}

Coeff coefficient; SE standard error; LLCI lower limit confidence interval; ULCI upper-limit confidence interval

the influence of the LC construct of motivation on the HRC constructs (Awareness: $\beta=0.5042 ; p<0.00$; Knowledge: $\beta=0.5172 ; p<0.0000$; and Motivation: $\beta=0.5305 ; p<0.000$ were also moderated by AdI (HIF). The highest moderated AdI (HIF) path was through the leadership construct of awareness on the HRC tenet of motivation. The bootstraps' confidence interval of LLCI and ULCI were all within significant moderation boundaries.

H4: Student demographics moderate the relationship between leadership capacity and $S E$

Finally, hypothesis 4 (H4) is also supported by the results presented in Table 7. The results show that the bootstrap confidence intervals are Significant, thus supporting that student demographics moderate the relationship between LC and SE. The bootstrap confidence intervals presented herein are Readiness: LLCI $=0.9949$, $\mathrm{ULCI}=1.3336 ;$ Awareness: $\mathrm{LLCI}=1.5017$, ULCI $=2.2534$; and Motivation: $\mathrm{LLCI}=0.6801, \mathrm{ULCI}=1.8250$.

The summarised results for the multiple moderated mediation is presented in Fig. 5. The results are shown for path ' $a$ '; path ' $b$ '; and for moderations only

Table 7 SD Moderating relationship between LC and SE

\begin{tabular}{lllllll}
\hline Moderator (SD) & Coeff & BootSE & $t$ & $p$ & LLCI & ULCI \\
\hline Readiness (Re) & 0.8306 & 1.1042 & -0.7522 & 0.0451 & 0.9949 & 1.3336 \\
Awareness (AWE) & 0.3759 & 0.9579 & 0.3924 & 0.0094 & 1.5017 & 2.2534 \\
Motivation(Mo) & 0.0724 & 0.8942 & 0.0810 & 0.0093 & 0.6801 & 1.8250 \\
\hline
\end{tabular}

Coeff coefficient; SE standard error; LLCI lower limit confidence interval; ULCI upper-limit confidence interval 


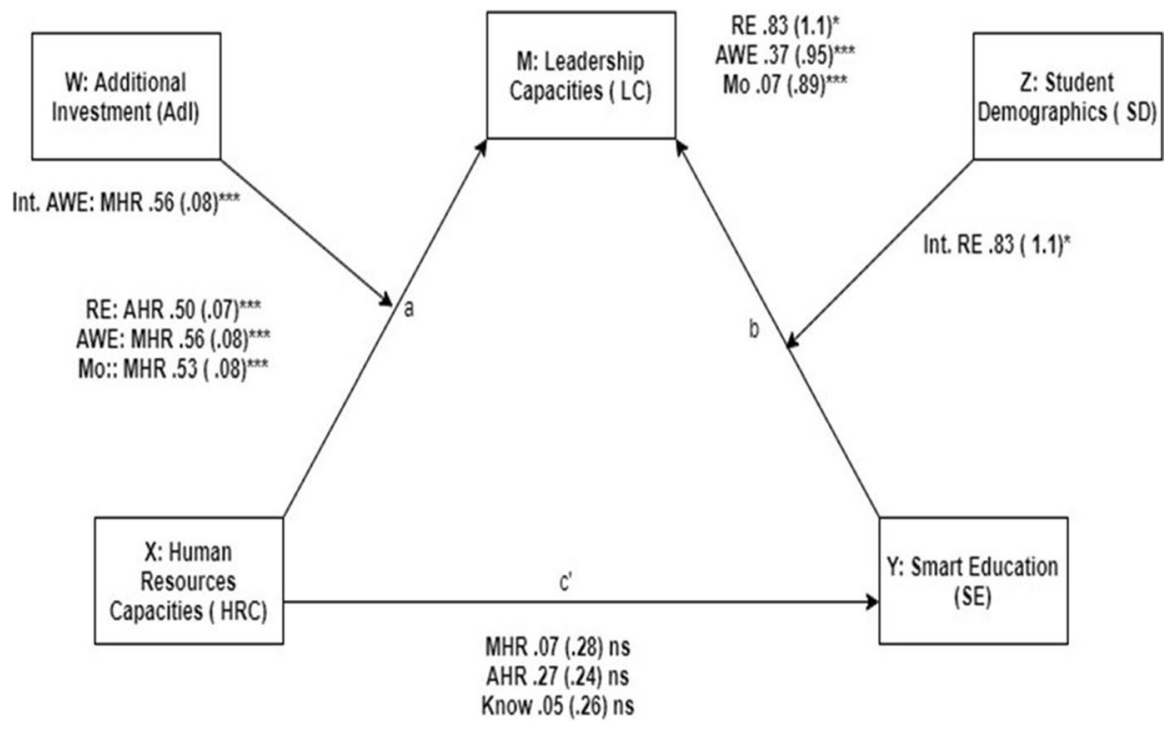

Fig 5 The multiple moderated mediation analysis (model 21 by Hayes, 2013). Note: Int. = Interaction; * $p<0.05$; *** $p<0.001$. MHR-motivation in HR; AHR-awareness in HR; Know-knowledge in HR; Rereadiness in leadership; AWE-awareness in leadership; Mo-motivation in leadership

consider the highest coefficients since HRC and LC's variables are measured in three constructs.

\section{Discussion}

Previous studies that assessed the application of SE (Zhu et al., (2016) \& Zhu et al., 2016b) ineffectively provided a holistic conceptual framework that satisfactorily demonstrated the influence of HRC and other participatory variables in SE's implementation. The present research drew from literature in e-government to develop an ANT supported structure that offered a unique framework that cogitated the TAM influence of HR, leadership, and moderating variables (AdI \& SD) in SE's adoption. Therefore, Fig. 5 above presents a proven path that can guide SE's implementation by building HR and leadership capacities; that work concurrently with investments in infrastructures and policy development.

The model has contributed to a better understanding of SE's implementation through the support of HRC's positive influence on SE (Alketbi, 2018; Wairiuko et al., 2018). Therefore, the capacities develop by human resources impact the success magnitude of SE. As such, an increase in the human resources capacity of awareness, knowledge, and motivation leads to an increase in SE's expediency and convenient application. For example, employees who are aware, motivated, and knowledgeable of SE portray greater familiarity, acceptance, and positive expectations of SE. However, despite the positive relationship between HRC and SE, results 
show that leadership mediates HRC's influence on SE, thus occupying the leading role in SE's implementation (Kakabadse et al., 2014; Lee \& Trimi, 2016).

Consequently, leadership constructs of readiness, awareness, and motivation are required to enhance HR's structures of knowledge, awareness, and motivation. The conditional indirect mediation demonstrates that SE's productive employment depends largely on proficient leadership, stimulating employees' readiness through knowledge enhancement in 1. Skills development in primary and advanced ICT, 2. Training sessions in smart pedagogies inclusion (Momani et al., 2016), and 3. Educational advancement (Yamoah, 2014). These knowledge enhancement strategies will aid in building capable, reliable, and efficient SE staff. Also, leadership builds awareness among HR through vision sharing that outlines the trajectory, goals, and benefits (Kakabadse et al., 2014) of SE. The interpretation of the results is that skills training leads to greater awareness of the vision and expectation of SE among employees (Lambert, n.d.). Likewise, leadership's role of building a shared vision among employees can lead to employees feeling a greater sense of belonging to SE's process; especially, if they are involved in the co-creation of SE's goals and feedback is considered valuable (Kakabadse et al., 2014)

For leadership to fully influence HRC's impact on SE, leadership needs to commit to additional investments in 1. Infrastructural development, 2. Policy development, 3. Strategic partnerships, and 4. public sensitization. In this way, employees can combat hindrances of lack of adequate technological resources (Plumb et al.), skills training (Plumb et al.), and lack of best practices. Without hard resources (Boes et al., 2016), employees will be unable to effectively and efficiently carry out their tasks. Notably, the development and availability of ICT infrastructure are compulsory (Plumb et al.) so that employees can fully adopt SE through the availability of software and hardware (Plumb et al.) that will enhance the use of smart pedagogies. However, additional investments as a moderator show that the lack of adequate technology infrastructures can limit employees' feedback.

Finally, the moderating effect of student demographics among the relationship of LC and SE can be interpreted as the administration's efforts on SE possibly will decrease if, ultimately, students are unable to access the gadgets and infrastructures needed to learn on such platforms. This inequitable access to devices and internet infrastructures may be due to factors such as learners' family income and place of residence (Hanafi \& Noor, 2016). Therefore, SE's policies must incorporate measures to assist less fortunate students in accessing these technological infrastructures.

\subsection{Research implications}

As COVID-19 continues to wreak havoc on many service industries worldwide, the education system is not spared. The past reality of most education systems was typified by the lamentable slow pace of change, such as the typical teaching method of the country's old lecture-based approaches entrenched in institutional biases and old classrooms. Presently, institutions and governments worldwide have started to 
rethink their teaching strategies; and have begun to search for and apply innovative solutions that can continue the teaching and learning process in a relatively short time frame. The realization that smart pedagogies such as virtual classrooms can combat the effects of COVID-19 has led to the oversight of crucial participatory variables such as HRC, thus missing the full contribution that these variables can offer. To conclude, a presentation of the theoretical and practical contributions garnered from this study is specified, trailed by limitations and future research directions.

\subsubsection{Theoretical implications}

The study presented herein confirms the ANT's premise that many people and things coagulate, harnessing a phenomenon's ecosystem. The ANT's proposition was supported through a multiple moderations conceptual mediation framework that presented significant relationships and interaction for many people and congealed things to influence SE's process. The study showed that the actions of people, HRC, and LC, and things, additional investments, and student demographics are significant participatory variables in SE's ecosystem. Therefore, the variables or actors possess equal influence to form networks that translate into the SE phenomenon. The obliteration of any of the variables can affect the overall results. Additionally, the sociotechnical ambitions of the ANT were also buttressed. The results demonstrated that the successful implementation of SE depends both on social variables such as HRC and LC; and technical variables such as investing in technological infrastructures such as computers.

The study also used TAM innovatively to assess how employees consider the influence of leadership and human resources capacities in SE's implementation. Most importantly, this paper adopted a strategic use of TAM's perceived usefulness variable by allowing it to act upon the external variables of leadership and human resources capacities. This adds new insight into the TAM theory by demonstrating that external variables do not always need to act upon the perceived usefulness belief of workers; but, the perceived usefulness belief of workers can act upon the external variable. This reordering of the variables is most useful in painting a clearer picture of how employees perceive the usefulness of external variables. Due to this rearranging of the TAM variables, a thorough analysis was conducted on the external variables' influence on SE's implementation.

\subsubsection{Managerial implications}

The general framework presented herein acknowledges a mixture of top-down and bottom-up managerial approaches in SE's execution. Therefore, since Grenada is seeking to adopt SE, the country needs to allocate sufficient power to leadership and HR to generate varying perspectives on SE's holistic adoption. Most importantly, 
leadership needs to garner the dimensions developed in this paper to achieve maximum capacity as well as inculcate in human resources the dimensions studied herein so that their capacity can also mature. When institutions and governments provide the obligatory responsiveness to HRC and LC variables, they can curtail barriers, such as lack of knowledge and skills (Plumb \& Kautz, 2015) that can affect the enactment of SE. Additionally, policy-makers in developing regions need to formulate guidelines that will help cater to less fortunate students by creating avenues to access technological infrastructures and gadgets easily. This study affirms that technology in education does not necessarily lead to equitable access to education, as alluded to by OECD (2016). Instead, learners who belong to the low family income group and who reside in underdeveloped communities will be disadvantaged in accessing education. Noteworthy to mention, neighbouring Caribbean islands can also use this knowledge when implementing SE since the islands share a similar culture and are within the same geographical location.

\subsection{Limitations and future research}

The results reported in this study are viewed through the sampling approach's lens as a significant limitation (Kotze, 2007). Based on statistical grounds, the small sampling size has restricted the results' generalizability to a larger population. Therefore, to enable the generalization of the findings, future research can specifically target a larger cross-sectional sample of workers from the educational industry. This cross-sectional sample can be observed through a longitudinal study that will assess leadership and human resources capacities in a real-world situation by observing the influence that these variables exhibit at varying academic stages. The longitudinal study's ultimate goal will be to assess learners' work performance in the workplace to rectify whether SE has helped expand skills compulsory to function in the Smart Machine Age (Hess, 2018). The SE participatory variables' realignment, with SE now occupying the independent variable position and work performance as a dependent, is envisioned. Researchers can also replicate this study in other small island developing regions to confirm the research findings' cogency. However, due to the similarity of the cultures, and population size of other small island countries in the Caribbean the results may be the same. The inclusion of a relative component will permit researchers to observe the similarities and differences among regions. See Tables 8, 9, 10, 11

\section{Appendix}




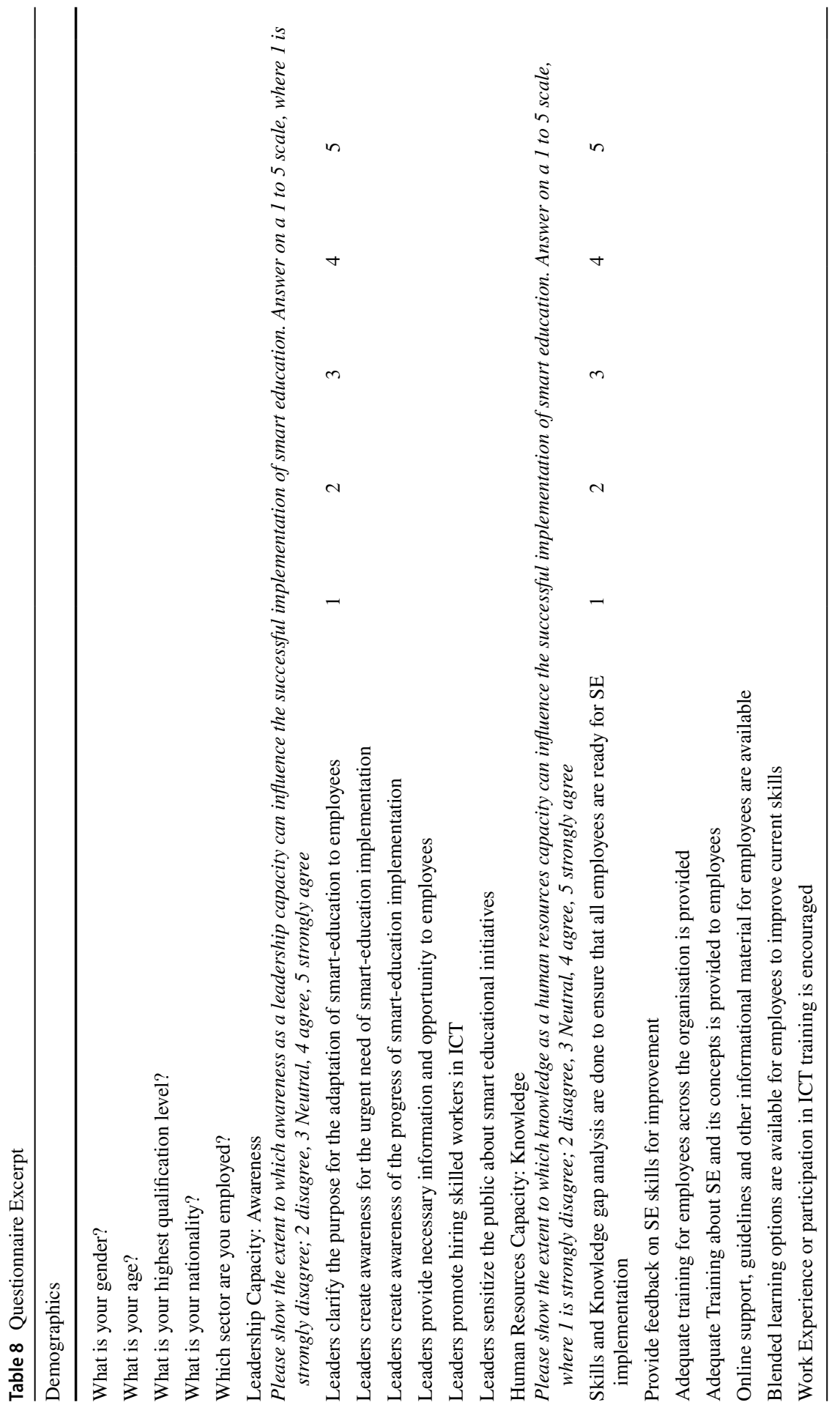


Table 9 An Excerpt of Pearson Correlation Validity Test Results (Leadership Awareness)

\begin{tabular}{|c|c|c|c|c|c|c|c|c|}
\hline \multicolumn{9}{|c|}{ Correlations } \\
\hline & & AL1 & AL2 & AL3 & AL4 & AL5 & AL6 & AL7 \\
\hline \multirow[t]{3}{*}{ AL1 } & Pearson Correlation & 1 & $0.797^{* *}$ & $0.781^{* *}$ & $0.772^{* * *}$ & $0.570^{* *}$ & $0.699^{* * *}$ & $0.756^{* *}$ \\
\hline & Sig. (2-tailed) & & 0.000 & 0.000 & 0.000 & 0.000 & 0.000 & 0.000 \\
\hline & $\mathrm{N}$ & 348 & 348 & 344 & 346 & 347 & 348 & 346 \\
\hline \multirow[t]{3}{*}{ AL2 } & Pearson Correlation & $0.797^{* *}$ & 1 & $0.850^{* *}$ & $0.773^{* *}$ & $0.619^{* *}$ & $0.661^{* *}$ & $0.702^{* *}$ \\
\hline & Sig. (2-tailed) & 0.000 & & 0.000 & 0.000 & 0.000 & 0.000 & 0.000 \\
\hline & $\mathrm{N}$ & 348 & 348 & 344 & 346 & 347 & 348 & 346 \\
\hline \multirow[t]{3}{*}{ AL3 } & Pearson Correlation & $0.781^{* *}$ & $0.850^{* * *}$ & 1 & $0.795^{* *}$ & $0.635^{* *}$ & $0.722^{* *}$ & $0.730^{* *}$ \\
\hline & Sig. (2-tailed) & 0.000 & 0.000 & & 0.000 & 0.000 & 0.000 & 0.000 \\
\hline & $\mathrm{N}$ & 344 & 344 & 344 & 342 & 343 & 344 & 342 \\
\hline \multirow[t]{3}{*}{ AL4 } & Pearson Correlation & $0.772^{* *}$ & $0.773^{* *}$ & $0.795^{* *}$ & 1 & $0.617^{* *}$ & $0.662^{* *}$ & $0.698^{* *}$ \\
\hline & Sig. (2-tailed) & 0.000 & 0.000 & 0.000 & & 0.000 & 0.000 & 0.000 \\
\hline & $\mathrm{N}$ & 346 & 346 & 342 & 346 & 345 & 346 & 344 \\
\hline \multirow[t]{3}{*}{ AL5 } & Pearson Correlation & $0.570^{* *}$ & $0.619^{* *}$ & $0.635^{* *}$ & $0.617^{* * *}$ & 1 & $0.607^{* * *}$ & $0.591^{* *}$ \\
\hline & Sig. (2-tailed) & 0.000 & 0.000 & 0.000 & 0.000 & & 0.000 & 0.000 \\
\hline & $\mathrm{N}$ & 347 & 347 & 343 & 345 & 347 & 347 & 345 \\
\hline \multirow[t]{3}{*}{ AL6 } & Pearson Correlation & $0.699^{* *}$ & $0.661^{* *}$ & $0.722^{* *}$ & $0.662^{* *}$ & $0.607^{* *}$ & 1 & $0.669^{* * *}$ \\
\hline & Sig. (2-tailed) & 0.000 & 0.000 & 0.000 & 0.000 & 0.000 & & 0.000 \\
\hline & $\mathrm{N}$ & 348 & 348 & 344 & 346 & 347 & 348 & 346 \\
\hline \multirow[t]{3}{*}{ AL7 } & Pearson Correlation & $0.756^{* *}$ & $0.702^{* * *}$ & $0.730^{* *}$ & $0.698^{* * *}$ & $0.591^{* *}$ & $0.669^{* *}$ & 1 \\
\hline & Sig. (2-tailed) & 0.000 & 0.000 & 0.000 & 0.000 & 0.000 & 0.000 & \\
\hline & $\mathrm{N}$ & 346 & 346 & 342 & 344 & 345 & 346 & 346 \\
\hline
\end{tabular}

**Correlation is significant at the 0.01 level (2-tailed) 
Table 10 An Excerpt of Pearson Correlation Validity Test Results (Leadership Motivation)

\begin{tabular}{llllllll}
\hline Correlations & ML1 & ML2 & ML3 & ML4 & ML5 & ML6 \\
\hline ML1 & Pearson Correlation & 1 & $0.834^{* *}$ & $0.749^{* *}$ & $0.674^{* *}$ & $0.719^{* *}$ & $0.703^{* *}$ \\
& Sig. (2-tailed) & & 0.000 & 0.000 & 0.000 & 0.000 & 0.000 \\
& N & 347 & 345 & 347 & 345 & 345 & 343 \\
ML2 & Pearson Correlation & $0.834^{* *}$ & 1 & $0.799^{* *}$ & $0.724^{* *}$ & $0.749^{* *}$ & $0.731^{* *}$ \\
& Sig. (2-tailed) & 0.000 & & 0.000 & 0.000 & 0.000 & 0.000 \\
& N & 345 & 345 & 345 & 343 & 343 & 341 \\
ML3 & Pearson Correlation & $0.749^{* *}$ & $0.799^{* *}$ & 1 & $0.679^{* *}$ & $0.702^{* *}$ & $0.673^{* *}$ \\
& Sig. (2-tailed) & 0.000 & 0.000 & & 0.000 & 0.000 & 0.000 \\
& N & 347 & 345 & 348 & 345 & 346 & 344 \\
ML4 & Pearson Correlation & $0.674^{* *}$ & $0.724^{* *}$ & $0.679^{* *}$ & 1 & $0.683^{* *}$ & $0.701^{* *}$ \\
& Sig. (2-tailed) & 0.000 & 0.000 & 0.000 & & 0.000 & 0.000 \\
& N & 345 & 343 & 345 & 345 & 343 & 341 \\
ML5 & Pearson Correlation & $0.719^{* *}$ & $0.749^{* *}$ & $0.702^{* *}$ & $0.683^{* *}$ & 1 & $0.763^{* *}$ \\
& Sig. (2-tailed) & 0.000 & 0.000 & 0.000 & 0.000 & & 0.000 \\
& N & 345 & 343 & 346 & 343 & 346 & 342 \\
ML6 & Pearson Correlation & $0.703^{* *}$ & $0.731^{* *}$ & $0.673^{* *}$ & $0.701^{* *}$ & $0.763^{* *}$ & 1 \\
& Sig. (2-tailed) & 0.000 & 0.000 & 0.000 & 0.000 & 0.000 & \\
& N & 343 & 341 & 344 & 341 & 342 & 344 \\
\hline
\end{tabular}

$* *$ Correlation is significant at the 0.01 level (2-tailed)

Table 11 An Excerpt of Pearson Correlation Validity Test Results (Smart Education)

\begin{tabular}{lllllll}
\hline Correlations & & & & & \\
\hline & & SE0 & SE1 & SE2 & SE3 & SE4 \\
\hline SE0 & Pearson Correlation & 1 & $0.834^{* *}$ & $0.749^{* *}$ & $0.674^{* *}$ & $0.719^{* *}$ \\
& Sig. (2-tailed) & & 0.000 & 0.000 & 0.000 & 0.000 \\
& N & 347 & 345 & 347 & 345 & 345 \\
SE1 & Pearson Correlation & $0.834^{* *}$ & 1 & $0.799^{* *}$ & $0.724^{* *}$ & $0.749^{* *}$ \\
& Sig. (2-tailed) & 0.000 & & 0.000 & 0.000 & 0.000 \\
& N & 345 & 345 & 345 & 343 & 343 \\
SE2 & Pearson Correlation & $0.749^{* *}$ & $0.799^{* *}$ & 1 & $0.679^{* *}$ & $0.702^{* *}$ \\
& Sig. (2-tailed) & 0.000 & 0.000 & & 0.000 & 0.000 \\
& N & 347 & 345 & 348 & 345 & 346 \\
SE3 & Pearson Correlation & $0.674^{* *}$ & $0.724^{* *}$ & $0.679^{* *}$ & 1 & $0.683^{* *}$ \\
& Sig. (2-tailed) & 0.000 & 0.000 & 0.000 & & 0.000 \\
& N & 345 & 343 & 345 & 345 & 343 \\
SE4 & Pearson Correlation & $0.719^{* *}$ & $0.749^{* *}$ & $0.702^{* *}$ & $0.683^{* *}$ & 1 \\
& Sig. (2-tailed) & 0.000 & 0.000 & 0.000 & 0.000 & \\
& N & 345 & 343 & 346 & 343 & 346 \\
\hline
\end{tabular}

**Correlation is significant at the 0.01 level (2-tailed) 
Acknowledgements Thank you to all respondents who participated in this research.

Author's contribution Conceptualization: Jonela Wilson; Methodology: Jonela Wilson, Jean Edjoukou; Formal analysis and investigation: Jonela Wilson, Patrick Kandege, Mussie Teklu; Writing - Jonela Wilson; Writing — review and editing: Jonela Wilson; Funding acquisition: N/A; Resources: Jonela Wilson; Supervision: Jonela Wilson.

Funding No funding was received to assist with the preparation of this manuscript.

Data availability statement Raw data were generated through the Google online survey platform. Derived data supporting the findings of this study are available from the first and corresponding author, J. Wilson, upon reasonable request.

\section{Code availability M52.}

\section{Declarations}

Informed consent Informed consent was received from all participants in this study.

Disclosure of potential conflicts of interest The authors have no conflicts of interest to declare that are relevant to the content of this article.

Research involving human participants and/or animals No humans or animals were harmed in conducting this study.

\section{References}

Abdullah, H. (2009). Major challenges to the effective management of human resource training and development activities. The Journal of International Social Research, 11-25.

Al-Jenaibi, B. (2016). Upgrading society with smart government: The use of smart services among federal offices of the UAE. International Journal of Information Systems \& Social Change, 20-51.

Alketbi,H.(2018, March5).An evaluation ofe-government effectiveness in Dubai smart government departments. Semantic Scholar. Retrieved January 6, 2020, from https://www.semanticscholar.org/paper/An-evaluationof-e-government-effectiveness-in-Alketbi/09179462853148a21987b1c9685598b022f6a68d

Bajaj, R., \& Sharma, V. (2018). Smart Education with artificial intelligence based determination of learning styles. Procedia Computer Science, 834-842.

Basset, M., Manogaran, G., Mohamed, M., \& Rushdy, E. (2018). Internet of things in Smart Education environment: Supportive framework in the decision-making process. Wiley Concurrency Computat Pract Exper, N/A.

Bdiwi, R., Runz, C., Faiz, S., \& Cherif, A. (2019). Smart learning environment: Teacher's role in assessing classroom attention. Research in Learning Technology, 27, 2072.

Bencherki, N. (2017). Actor-network theory. The International Encyclopedia Organizational Communication, NA.

Boes, k., Buhalis, D., \& Inversini, A. (2016). Smart Tourism Destinations: Ecosystems for Tourism Destination Competitiveness. International Journal of Tourism Cities, 108-124.

Budhrani, K., Ji, Y., \& Lim, J. (2018). Unpacking conceptual elements of smart learning in the Korean scholarly discourse. Smart Learning Environments, 1-26.

Callon, M. (1999). Actor-Network Theory-the market test. Blackwell Publishers.

Casanova, F., Linares, M., Torre, M., \& Carpio, M. (2005). Influence of family and socio-demographic variables on students with low academic achievement. An International Journal of Experimental Psychology, 423-435.

CGTN. (2020, May 5). COVID-19 vs. Globalization. Youtube. Retrieved May 28, 2020, from https:// www.youtube.com/watch?v=sGhEZGCzVd8\&pbjreload=10\&google_abuse=GOOGLE_ABUSE_ EXEMPTION\%3DID\%3Df15eb89a507f51f0\%3ATM\%3D1590588255\%3AC\%3Dr\%3AIP\% 
3D2a01\%3A4f8\%3A1c17\%3A530d\%3A\%3A1-\%3AS\%3DAPGng0u7Jbi36t-UoIuxD_nc7vhHmh_ Hbw $\% 3 \mathrm{~B}+$ path $\% 3 \mathrm{D} \% 2 \mathrm{~F} \% 3 \mathrm{~B}+$ domain $\% 3 \mathrm{Dgoogl}$

Chatfield, A., \& Reddick, C. (2018, September 18). A framework for Internet of Things-enabled smart government: Acase of IoT. Elsevier Inc. Retrieved February 8, 2020, from https://doi.org/10. 1016/j.giq.2018.09.007

Chi, Y., Qin, Y., Song, R., \& Xu, H. (2018). Knowledge graph in smart education: A case study of entrepeneurship scientific publication. Sustainability, 1-21.

Choi, B., Yeo, D., \& Wu, D. (2018). The Implications of ANT ( Actor-Network Theory) Methodology for R\&D Policy in Open Innovation Paradigm. Knowledge Management Research and Practice, 16(3), 315-326.

Costa, C., \& Cunha, P. (2009). Business Model Design from an ANT Perspective: Contributions and Insights of an Open and Living Theory. SIGeBI2 track of the Americas Conference on Information Systems AMCIS 2009: Value Creation in E-Business Management (pp. 56-67). San Francisco : Springer.

Creswell, K., Worth, A., \& Sheikh, A. (2010). Actor-Network Theory and its role in understanding the implementation of information technolgy developments in healthcare. Medical Informatics \& Decision Making, 10(67), 1472-6947.

Davis, F. (1985, January 04). A Technology Acceptance Model for Empirically Testing New End-User Information Systems: Theory \& Results. ResearchGate. Retrieved December 12, 2019, from https:// www.researchgate.net/publication/35465050

D. Capital Partners. (2013, NA NA). Impact investing in education: An overview of the current landscape. Retrieved from Open Society Foundation: https://www.opensocietyfoundations.org/publications/ impact-investing-education-overview-current-landscape

Esnault, L., Zeiliger, R., \& Vermeulin, F. (2006). On the use of actor-network theory for developing web services dedicated to communities of practice. EC-TEL Workshop Proceedings (pp. 298-306). ECTEL: France.

Fenwick, T., \& Edwards, R. (2010). Actor-Network in Education. Routledge.

Finogeev, A., Kravets, A., Deev, M., Bershadsky, A., \& Gamidullaeva, L. (2018). Life-cycle management of educational programs \& resources in a smart learning environment. Smart Learning Environments, 1-10.

Folden, R. (2012). General Perspective in Learning Management Systems. In R. Babo, \& A. Azevedo, Higher Education Institutions \& Learning Management Systems: Adoption \& Standardization (p. N/A). New York: Information Science Reference.

Garcia, J., Zhang, J., \& Cid, G. (2016). Conceptualizing smartness in government: An integrative and multi-dimensional view. Elsevier Government Quarterly, 524-534.

Giannakos, M., Sampson, D., \& Kidzinski, L. (2016). Introduction to smart learning analytics: foundations and developments in video-based learning. Smart Learning Environments, 1-9.

Government of Grenada . (2018). Grenada's Budget Report 2018. St. George's: Government of Grenada.

Government of Grenada. (2019). Grenada's Budget Report 2019. St. George's: Government of Grenada.

Hanafi, Z., \& Noor, F. (2016). Relationship between demographic factors and emerging adult's academic achievement. International journal of academic research in business and social sciences, 2222-6990.

Hayes, A. (2013). Introduction to Mediation, Moderation, and Conditional Process Analysis: A RegressionBased Approach. Guilford Publications Inc.

Hess, E. (2018, March -). A NSW Government Webiste. Transforming School Education for the Smart Machine Age. Retrieved November 15, 2019, from https://education.nsw.gov.au/teaching-andlearning/education-for-a-changing-world/resource-library/transforming-school-education-forthe-smart-machine-age

Hoel, T., \& Mason, J. (2018). Standards for smart education-towards a development framework. Smart Learning Environments, 5, 1-25.

Hubert, M., Blut, M., Brock, C., Zhang, R., Koch, V., \& Riedl, R. (2018). The Influence of Acceptance and Adoption Drivers on Smart Home Usage. European Journal of Marketing, 53(6), 1073-1098.

IBM Australia. (NA). Smart Education Australia. Sydney: IBM Australia.

Information Polity. (2016). Smartness in Governance, Government, Urban Environments, and the Internet of Things: An Editorial Introduction. IOS Press.

Jonker, J., \& Pennink, B. (2010). The essence of research methodologies -A concise guide for master and phd students in management science. Springer. 
Kakabadse, A., Abdulla, M., Abouchakra, R., \& Jawad, A. (2014). Leadinng smart trnasformation: A roadmap for world class government. Palgrave Macmillan.

Kats, Y. (2010). Learning Management System Technologies and Software Solution for Online Teaching Tools \& Applications. Information Science Reference.

Kimaro, H. (2006). Strategies for developing human resource capacity to support sustainaibility of ICT based health information systems: A case from Tanzania. The Electronic Journal of Information Systems in Developing Countries, 1-23.

Kiryakova, G., Angelova, N., \& Yordanova, L. (2018). The potential of Augmented Reality to transform education into smart education. TEM Journal, 556-565.

Kotze, T. (2007). Guidelines on writing a first quantitative academic article. University of Pretoria.

Koul, S., \& Eydgahi, A. (2018). Utilizing Technology Acceptance Model (TAM) for Driverless Car Technology Adoption. Journal of Technology Management and Innovation, 13(4), 37-46.

Kumar, R. (2011). Research methodology a step-by-step guide for beginners. Sage.

Lai, J., \& Bower, M. (2019). How is the use of technology in education evaluated? A Systematic Review. Computer \& Education, 27-42.

Lai, P. (2017). The literature review of technology adoption models and theories for the novelty technology. Journal of Information Systems \& Technology Management, 21-38.

Lambert, L. (n.d.). Lasting leadership: A study of high leadership capacity schools. The Educational Forum, 238-254.

Latour, B. (1996). On Actor-Network Theory. A Few Clarifications Plus More than a Few Complications. In Finn Olsen-Danish Philosophy Journal, 25(3), 47-64.

Law, J. (2007). Actor-Network Theory and Material Semiotics. Lancester University. Retrieved May 5 , 2021, from http://www.heterogeneities.net/publications/Law2007ANTandMaterialSemiotics.pdf

Liao, S., Hong, J. W., Pan, Y., \& Wu, Y. (2018). Applying Technology Acceptance Model (TAM) to Explore User's Behavioral Intention to Adopt a Performance Assessment System for E-book Publication. Eurasia Journal of Mathematics, Science and Technology Education, 14(10), 1-12.

Leahy, M., Davis, N., Lewin, C., Charania, A., Nordin, H., Orlic, D., Lopez, O. (2016). Smart partnerships to increase equity in education. Educational Techology \& Society, 84-98.

Lee, J., \& Kim, S. (2015). Validation of a tool evaluating educational apps for smart education. Journal of Educational Computing Research, 1-16.

Lee, S., \& Trimi, S. (2016). Innovation for creating a smart future. Journal of Innovation \& Knowledge, 1-8.

Leem, J., \& Sung, E. (2019). Teacher's belief's and technology acceptance concerning smart mobile devices for SMART education in South Korea. British Journal of Educational Technology, 601-613.

Li, X., Wang, F., \& Gu, X. (2019). Understanding the roles of ICT enterprises in promoting the ICT industry ecosystem in education: Case studies from China. British Journal of Educational Technology, 1151-1172.

Lim, C., Chai, C., \& Churchill, D. (2011). A framework for developing pre-service teacher's competence in using technologies to enhance teaching \& learning. Educational Media International, 69-83.

Lin, J., Pu, H., Li, Y., \& Lian, J. (2018). Intelligent Recommendation System for Course Selection in Smart Education. 2017 International Conference on Identification, Information, \& Knowledge in the Internet of Things (pp. 449-453). N/A: Elsevier; Science Direct, Procedia Computer Science.

Momani, M., Alshaikhi, T., \& Al-Inizi, T. (2016). The obstacles of using smart board in teaching english at Tabuk secondary schools. Asian Journal of Educational Research, 22-39.

OECD. (2016). Innovating education and educating for innovation: The power of digital technologies. OECD Publishing.

Olaniyi, A. (2019). Application of likert scale's type and cronbach's alpha analysis in an airport perception study. Scholar Journal of Applied Sciences \& Research, 01-05.

Park, S., \& Ertmer, P. (2008). Examining barriers in technology-enhanced problem-based learning: Using a performance support systems approach. British Journal of Educational Technology, 631-643.

Plumb, M., \& Kautz, K. (2015). Barriers to the integration of IT within early childhood education and care organizations: A review of the literature. Australasian Conference of Information Systems . Sydney: Australasian Conference of Information Systems.

Price, J. (2015). Transforming learning for the smart learning environment: lessons learned from the intel education initiatives. Learning Environments, 1-16. 
Saunders, M., Lewis, P., \& Thornhill, A. (2009). Research methods for business students. Pearson Education Limited.

Scholl, J., \& Scholl, C. (2014). Smart Governeance: A Roadmap for Research and Practice. iConference (pp. 163-176). NA: NA.

Schultz, D., \& Schultz, S. (2010). Psychology and Work Today: An Introduction to Industrial and Organizational Psychology. Pearson Education Inc.: Upper Saddle River, NJ, USA.

Seuwou, P., Banissi, E., Ubakanma, G., Sharif, M., \& Healey, A. (2017). Actor-Network Theory as a Framework to Analyse Technology Acceptance Model's External Variables: The Case of Autonomous Vehicles. In H. Jahankhani, A. Carlile, D. Emm, A. Hosseinian-Far, G. Brown, G. Sexton, \& A. Jamal (Eds.), Global Security, Safety and Sustainability - The Security Challenges of the Connected WorldICGS3 2017 Proceedings. Springer International Publishing: New York, NY, USA.

Shah, V., \& Shah, A. (2018, June 12). Relationship Between Student Perception of School Worthiness and Demographic Factors. Frontiers in Education. Retrieved October 12, 2019, from https:// www.frontiersin.org/articles/10.3389/feduc.2018.00045/full

Singh, H., \& Miah, S. (2020). Smart education: A theoretical analysis. Education and Information Technologies, 25, 3299-3328.

Smith, I. (2005). Achieving readiness for organizational change. Library Management, 408-412.

Steffens, K. (2008). Technology Enhanced Learning Environments for Self Regulated learning: a framework for research. Technology, Pedagogy and Education, 221-232.

UNESCO. (2020, March 12th). Education: From Disruption to Recovery. UNESCO. Retrieved from https://en.unesco.org/covid19/educationresponse

United Nations. (2018, July 19). United Nations E-Government Survey. United Nations Department of Economics and Social Affairs. Retrieved August 13, 2019, from https://www.un.org/development/ desa/publications/2018-un-e-government-survey.html

Uskov, V., Howlet, R., \& Jain, L. (2015). Smart Innovation, Systems \& Technology. Springer International Publishing.

Wairiuko, J., Nyonje, R., \& Omulo, E. (2018). Human Resource Capacity and Adoption of E-Government for Improved Service Delivery in Kajiado County, Kenya. International Journal of Business and Social Science, 94-110.

Wang, X., Wilson, J., \& Li, W. (2021). An Empirical Investigation of Leadership and Human Resources Capacities as Key Actors in the Implementation of Smart Education. Education in Science, 11, 138. https://doi.org/10.3390/educsci11030138

World Economic Forum. (2020, March 26th). COVID-19's Staggering Impact on Global Education. World Economic Forum. Retrieved from https://www.weforum.org/agenda/2020/03/infographiccovid19-coronavirus-impact-global-education-health-schools/

Yaghi, A., \& Al-Jenaibi, B. (2018). Happiness, morality, rationality, and challenges in implementing smart government policy. Public Integrity, 284-299.

Yamoah, E. (2014). The Link Between Human Resource Capacity and Job Performance. The International Journal of Human Resource Studies.

Yusufu, G., \& Zeeshan, S. (2019). New development and evaluation model for self-regulated smart learning environment in higher education. Global Engineering Education Conference (pp. 990-994). Scotland: University of the West of Scotland.

Zhu, Z., Sun, Y., \& Riezebos, P. (2016). Introducing the smart education framework: core elements for successful learning in a digital world. International Journal of Smart Technology and Learning, 53-66.

Zhu, Z., Yu, M., \& Riezebos, P. (2016). A research framework of smart eduation. Smart Learning Environments, 1-17.

Publisher's Note Springer Nature remains neutral with regard to jurisdictional claims in published maps and institutional affiliations. 


\section{Authors and Affiliations}

\section{Jonela Carmada Marisa Wilson ${ }^{1}$ (D) Patrick Kandege ${ }^{2}$ (D)}

Akadje Jean Roland Edjoukou ${ }^{3} \cdot$ Mussie Tesfay Teklu $^{1}$

Patrick Kandege

pkandege1@gmail.com

Akadje Jean Roland Edjoukou

edjoukou2015@yahoo.fr

Mussie Tesfay Teklu

mussie1909@gmail.com

1 School of Business Administration, Dongbei University of Finance and Economics, Dalian, PR, China

2 School of Mathematics, Dalian University of Technology, Dalian, PR, China

3 School of Accounting, Dongbei University of Finance and Economics, Dalian, PR, China 